\title{
Dynamic friction coefficients of grain crops of bulk agricultural products
}

\author{
Dmitriy Savenkov ${ }^{1, *}$, Oleg Kirischiev ${ }^{1}$, Valentina Serdyuk ${ }^{1}$, Aleksey Shcherbakov ${ }^{1}$, Dmitriy \\ Kirillov ${ }^{1}$ \\ ${ }^{1}$ Don State Technical University, 1, pl. Gagarina, 344003, Rostov-on-Don, Russia
}

\begin{abstract}
The article covers issues related to the study of physical and mechanical characteristics of bulk materials, namely the coefficients of external friction in static and dynamic modes. The program, methodology and results of research on the practical study of external friction coefficients of typical agricultural grain products by the surfaces made of materials typical for the working bodies of production machines, using an innovative carousel-type device, are presented. As a result of research, it was found that in the range of linear speeds from 0 to $1.75 \mathrm{~m} / \mathrm{s}$, there is a change in the friction coefficients, which has a nonlinear character.
\end{abstract}

\section{Introduction}

Working bodies of agricultural and processing machines interact directly with grain processed materials. Therefore, the physical and mechanical properties of such materials are taken into account when designing and operating machines. One of the indicators that characterize these properties is the coefficient of friction, since its value determines the processes of moving grain materials and outflow from the bins [1-4].

Friction is one of the most common physical phenomena in agriculture. The sliding friction force is always directed opposite to the movement of the body and prevents its movement, which can lead to an increase in energy consumption or even to a stop of a working process. In this regard, determining the friction characteristics of bulk materials is an urgent task.

There is a wide variety of installations for determining the friction characteristics of bulk materials, which are based on three methods for measuring the coefficient of friction: on an inclined plane, in an embankment, and by torsion. Based on the analysis of such installations, it can be concluded that the determination of the dynamic coefficient of friction on that installations is either impossible or involves great technical difficulties, leading to a decrease in the reliability of the result obtained. At the same time, existing installations do not allow obtaining data on friction coefficients at speeds that are achieved in real conditions of processing grain materials, when the speed of moving bulk material relative to the working body can reach up to $15 \mathrm{~m} / \mathrm{s}$ or more.

The purpose of the study is to identify the nature of the dependence of the dynamic coefficient of friction on the speed of displacement of agricultural grain products by the

\footnotetext{
* Corresponding author: savenkov-dstu@yandex.ru
} 
surfaces made of materials typical for the working bodies of production machines.

\section{Materials and methods}

To achieve the research goal, an innovative device for determining the friction characteristics of bulk materials was designed and manufactured [5-8]. The working body of this device is a driving, rotating cup with the test surface fixed to its butt, and the hollow cylinder with partitions (cage) for bulk material installed on it, which is connected to the dynamometer, figure 1 . In such a device, the bulk material is guaranteed to shift relative to the test surface and the shear force is measured at the boundary between the rotating cup and the cylinder, due to the exclusion of uncontrolled material shift relative to the cylinder.

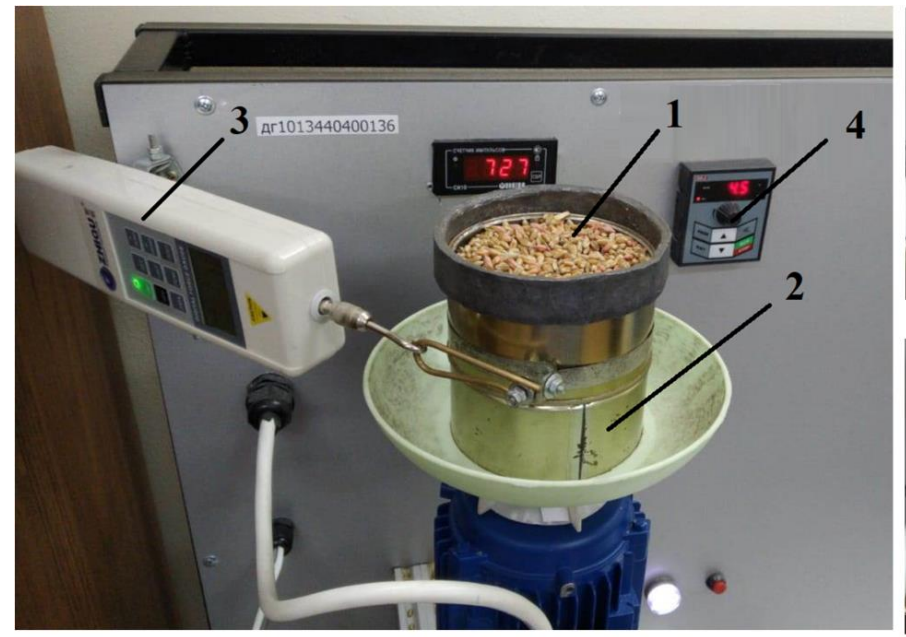

a)

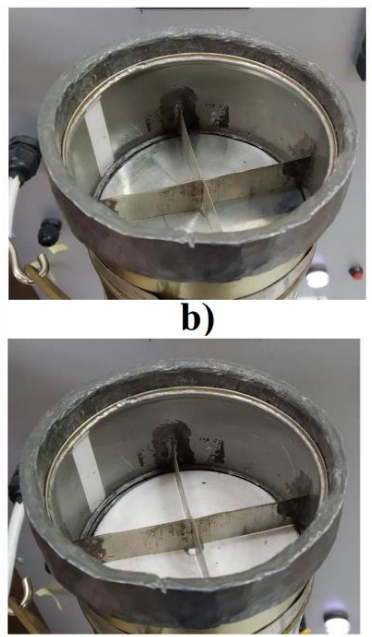

c)

Fig. 1. a) The general view of the device to determine the effect of the layer displacement rate on the dynamic friction coefficient of bulk products. 1 - holder of friction device; 2 - cup; 3 - dynamometer; 4 - the regulator of speed of rotation of the cup; b) steel friction; c) plastic friction.

The main feature of this device is to ensure the accuracy of the results of studies of the frictional characteristics of bulk materials: the coefficient of external friction of rest and the coefficient of external friction of the movement of bulk material on various rigid materials.

When conducting research, a sample of the test surface is placed on the end of the Cup, and the grain product is poured into the cylinder which is connected to a dynamometer with a digital display for displaying the values of the force of interaction between the grain and the surface.

The linear speed of grain displacement on the test surface is determined by calculating using the frequency rotation of the Cup $[9,11]$

At the first stage, the study of the dependence of the force on the dynamometer on the speed of rotation of the Cup without loading the cylinder with the material under study, which allowed us to determine the correction characteristic in the form of the idling force of the installation due to its design. The correction is defined as the amount of force on the dynamometer $(\mathrm{N})$ at a given speed of rotation of the Cup (v), loaded only by the proper weight of the cylinder.

As a result of the conducted research, it was found that in the range of rotation speeds $v$ from 0 to $350 \mathrm{~min}-1$, the idling force of the installation does not change significantly and varies in the range from 0.55 to $0.65 \mathrm{~N}$. The average force value of $0.62 \mathrm{~N}$ is accepted as 
the idling value for making an amendment to the results of studies with grain products. The correction for measuring the static coefficient of friction at $v=0$ is not applied $(\mathrm{N}=0)$.

\section{Results}

Determination of external friction coefficients was carried out on typical agricultural grain products by the surfaces made of materials typical for working bodies of production machines.

Grain crops were used during the experiments: grain crops with bare or filmy grainwheat, barley.

Polished steel and plastic were studied as typical materials of working bodies.

Methods of conducting experiments:

1. A sample of the test surface from the typical material of the working parts is placed on the Cup to the level of the cage partitions.

2. A measured portion of the test material weighing $\mathrm{m}$ is filled into the cage.

3. The Cup rotation drive is activated.

4. The specified speed of rotation $n$ is set.

5. The force is measured on the dynamometer (S) at least 3 times in 30 seconds and the results are recorded in the $\log$.

The static coefficient of friction is measured at the moment corresponding to the initial Cup shift. That is, the shear force corresponding to the zero displacement rate is measured. Further experiments are carried out with discrete values of the Cup rotation frequency, which are set based on the design capabilities of the installation. The maximum speed achieved during the experiments is $500 \mathrm{~min}-1$, which corresponds to a linear speed of 1.75 $\mathrm{m} / \mathrm{s}$.

Upon completion of the experiments, the following procedures are performed for each grain product:

1. The average value of the force on the dynamometer $\mathrm{Y}$ is calculated at a given speed.

2. The correction of the idle speed force of the unit is made and the force on the dynamometer $(\mathrm{T})$ corresponding to the friction force is determined.

3. The friction force $(F)$ is calculated from the condition that the moment of friction is balanced by the moment of force on the dynamometer

$$
F=T \frac{3 R}{2 r}
$$

where $R$ - radius of the place where the dynamometer is attached to the cage $(R=60 \mathrm{~mm}), r$ - radius of the cage $(\mathrm{r}=50 \mathrm{~mm})$ [12].

4. The linear velocity $(\mathrm{V})$ of the mass center of the material portion is calculated.

5 . The value of the dynamic coefficient of friction ( $k$ ) for each speed is calculated using the formula:

$$
\mathrm{k}=\mathrm{F} / \mathrm{N}
$$

where: $\mathrm{N}$ - gravity of the material portion in the cage, $\mathrm{g}$ - acceleration of gravity) [13-16].

6. Construction of models of dependence $k=f(V)$ for each material is performed.

7. In order to obtain information about changes in the tribological characteristics of bulk products in the dynamics in a more familiar form for the user, the internal friction angles $(\varphi)$ for each product are calculated using a well-known formula:

$$
\varphi=\operatorname{arctg}(k)
$$




\section{Discussion of the results}

The results of experiments to determine the dependence of the dynamic coefficient of friction on the velocity of moving of grain materials are presented in the form of tables 1-4 and graphs 2,3 . The graphs of a function $k=f(V)$ written as $y=f(x)$.

Table 1. Coefficient of friction of barley by plastic.

\begin{tabular}{|c|c|c|c|}
\hline Experiment & V. $\mathbf{m} / \mathbf{s}$ & $\mathbf{k}$ & $\boldsymbol{\varphi . ~ d e g r e e s}$ \\
\hline 1 & 0.00 & 0.26 & 14.6 \\
\hline 2 & 0.105 & 0.2 & 1.1 \\
\hline 3 & 0.44 & 0.31 & 17.2 \\
\hline 4 & 0.66 & 0.84 & 40.0 \\
\hline 5 & 0.9 & 1.1 & 58.0 \\
\hline
\end{tabular}

Table 2. Coefficient of friction of wheat by plastic.

\begin{tabular}{|c|c|c|c|}
\hline Experiment & $\mathbf{V} . \mathbf{m} / \mathbf{s}$ & $\mathbf{k}$ & $\boldsymbol{\varphi . ~ d e g r e e s}$ \\
\hline 1 & 0.105 & 0.08 & 4.6 \\
\hline 2 & 0.38 & 0.37 & 20.3 \\
\hline 3 & 0.66 & 0.71 & 35.4 \\
\hline 4 & 0.91 & 0.71 & 35.4 \\
\hline 5 & 1.155 & 0.745 & 26.6 \\
\hline 6 & 1.4 & 0.78 & 38.0 \\
\hline
\end{tabular}

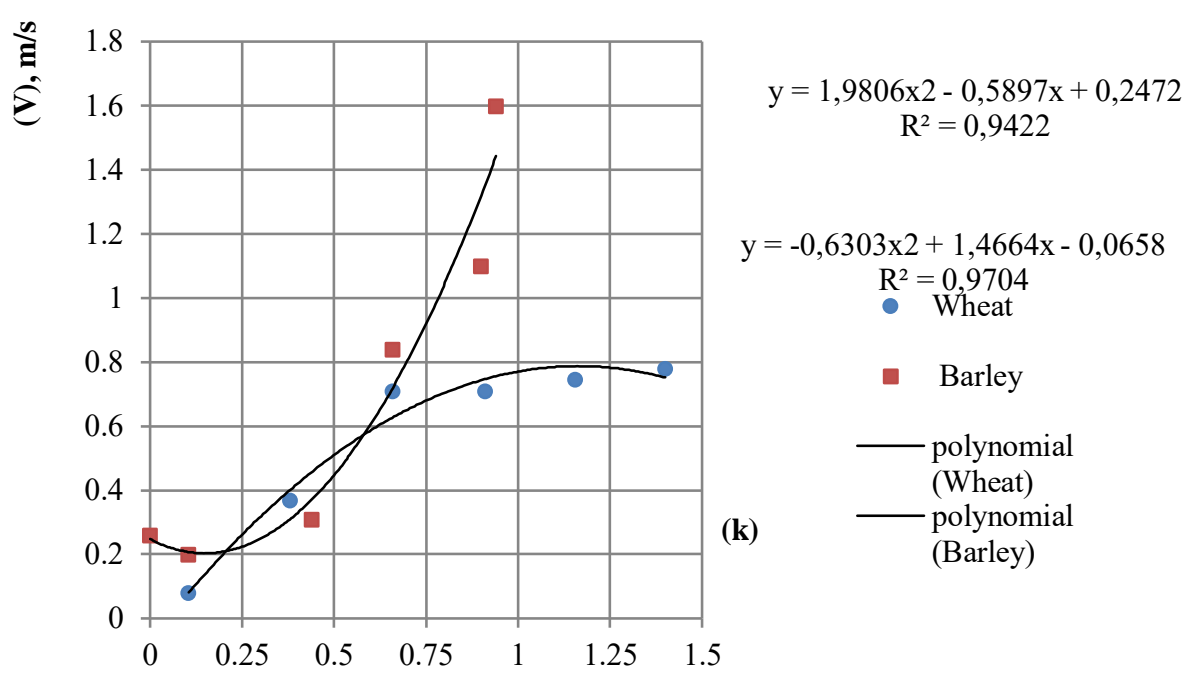

Fig. 2. Dependence of the coefficient of friction of wheat and barley by plastic.

Table 3. Coefficient of friction of wheat by steel.

\begin{tabular}{|c|c|c|c|}
\hline Experiment & V. m/s & $\mathbf{k}$ & $\boldsymbol{\varphi}$. degrees \\
\hline 1 & 0.00 & 0.05 & 2.9 \\
\hline 2 & 0.209 & 0.09 & 25.2 \\
\hline 3 & 0.42 & 0.47 & 36.5 \\
\hline 4 & 0.63 & 0.74 & 47.2 \\
\hline
\end{tabular}




\begin{tabular}{|c|c|c|c|}
\hline 5 & 0.84 & 1.08 & 51.1 \\
\hline 6 & 1.12 & 1.24 & 53.1 \\
\hline 7 & 1.4 & 1.33 & 59.4 \\
\hline
\end{tabular}

Table 4. Coefficient of friction of barley by steel.

\begin{tabular}{|c|c|c|c|}
\hline Experiment & $\mathbf{V . ~ m} / \mathbf{s}$ & $\mathbf{k}$ & $\boldsymbol{\varphi . d e g r e e s}$ \\
\hline 1 & 0.01 & 0.35 & 19.3 \\
\hline 2 & 0.209 & 0.76 & 37.2 \\
\hline 3 & 0.52 & 0.87 & 41.0 \\
\hline 4 & 0.77 & 0.83 & 39.7 \\
\hline 5 & 0.98 & 0.87 & 41.0 \\
\hline 6 & 1.19 & 0.79 & 38.3 \\
\hline 7 & 1.4 & 0.85 & 45.0 \\
\hline 8 & 1.61 & 0.82 & 39.4 \\
\hline
\end{tabular}

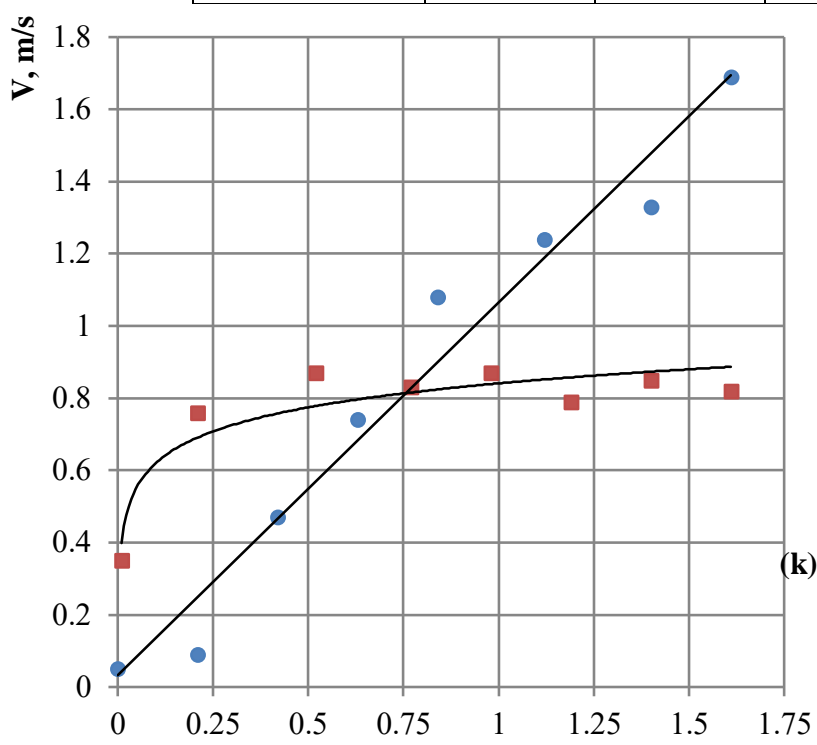

$\mathrm{y}=1.0322 \mathrm{x}+0.0326$ $\mathrm{R}^{2}=0.9659$

$\mathrm{y}=0,096 \ln (\mathrm{x})+0,841$

- $\mathrm{R}^{2}=0,8741$

- Barley

- polynomial (Wheat)

- logarithmic (Barley)

Fig. 3. Dependence of the coefficient of friction of wheat and barley by steel.

\section{Conclusions}

1. Dependence of external friction coefficients of typical agricultural grain products by the surfaces made of materials typical for working bodies of production machines on the speed of displacement in the range from 0 to $1,75 \mathrm{~m} / \mathrm{s}$ it is non- linear in nature.

2. The values of $\mathrm{k}$ that are closest to real data for all materials give by exponential and polynomial models of the second order.

Table 5. The generalized results of the experiments.

\begin{tabular}{|c|c|c|}
\hline Product & Surface & Model \\
\hline \multirow{2}{*}{ Wheat } & Steel & $\mathrm{y}=1.0322 \mathrm{x}+0.0326 \mathrm{R}^{2}=0.9659$ \\
\cline { 2 - 3 } & Plastic & $\mathrm{y}=-0.6303 \mathrm{x}^{2}+1.4664 \mathrm{x}-0.0658 \mathrm{R}^{2}=0.9704$ \\
\hline \multirow{2}{*}{ Barley } & Steel & $\mathrm{y}=0.096 \ln (\mathrm{x})+0.841 \mathrm{R}^{2}=0.8741$ \\
\cline { 2 - 3 } & Plastic & $\mathrm{y}=1.9806 \mathrm{x}^{2}-0.5897 \mathrm{x}+0.2472 \mathrm{R}^{2}=0.9422$ \\
\hline
\end{tabular}


3. The device of carousel type for determination of frictional characteristics of bulk materials allows to score problems of practical determination of dynamic coefficients of friction of the investigated bulk products of agricultural production in the range of speeds from 0 to $2,79 \mathrm{~m} / \mathrm{s}$ with reliability $\mathrm{R}^{2}$ not lower then 0.878 .

\section{References}

1. A. Doroshenko, MATEC Web of Conferences (ICMTMTE 2018) 224, 05023 (2018)

2. D. Savenkov, MATEC Web of Conferences (ICMTMTE 2018) 224, 05023 (2018)

3. X. Liu, Journal of Materials Science \& Technology 35, 1412-1421 (2019)

4. H. Baek, International Journal of Solids and Structures 144-145, 86-99 (2018)

5. C. Menapace, Wear 398-399, 191-200 (2018)

6. K. Saw, Materails today: processing 5, 24094-24103 (2018)

7. K. Senetakis, Tribology International 111, 1-8 (2017)

8. A. Vakis, Tribology International 125, 169-199 (2018)

9. S. Zhang, Materails today (2018)

10. U. Nirmal, Tribology International 83, 77-104 (2015)

11. T. Mills, Woodhead Publishing Series in Food Science, Technology and Nutrition, 292-309 (2013)

12. D. Savenkov, E3S Web of Conferences (ITESE-2019) 135, 01102 (2019)

13. B. Winkeljann, Biotribology 14, 11-18 (2018)

14. P. Udaykant, Tribology International 126, 240-248 (2018)

15. Yu.A. Ivanov, MATEC Web of Conferences (ICMTMTE 2018) 224, 05023 (2018)

16. S. Ivanov, I. Kambulov, MATEC Web of Conferences (ICMTMTE 2018) 224, 05022 (2018) 